\title{
Occurrence and Fate of Antibiotics as Trace Contaminants in Wastewaters, Sewage Sludges, and Surface Waters
}

\author{
Walter Giger*, Alfredo C. Alder, Eva M. Golet, Hans-Peter E. Kohler, Christa S. McArdell, \\ Eva Molnar, Hansrudolf Siegrist, and Marc J.-F. Suter
}

\begin{abstract}
Environmental analytical studies show that trace concentrations of antibacterial agents (antibiotics) occur in hospital and municipal wastewaters and in the aquatic environment. Fluoroquinolones and macrolides, two important human-use antibiotic classes, were studied in detail. The results are discussed regarding input sources and behavior in wastewater treatment and rivers. The fluoroquinolones ciprofloxacin and norfloxacin are substantially eliminated in wastewater treatment (80-90\%) by sorption transfer to sewage sludge. In digested sludges the fluoroquinolones occur at $\mathrm{mg} / \mathrm{kg}$ levels. Ciprofloxacin and norfloxacin are further removed in the Glatt river by 66 and $48 \%$, respectively. The most abundant macrolide clarithromycin was detected at 57 to $330 \mathrm{ng} / \mathrm{l}$ concentrations in treated wastewater effluents. Different compositions of the macrolides (clarithromycin and erythromycin- $\mathrm{H}_{2} \mathrm{O}$ ) determined in treated effluents of three wastewater treatment plants can be explained by distinct consumption patterns, in one case due to an international airport located in the catchment area. Residual levels of clarithromycin in the Glatt river were up to $75 \mathrm{ng} / \mathrm{l}$ with no apparent removal in the river. These results provide important information on environmental exposures, which can be incorporated into environmental risk assessments of the particular chemicals.
\end{abstract}

Keywords: Ciprofloxacin · Clarithromycin · Fluoroquinolones · Macrolides · Norfloxacin

\section{Introduction}

For more than 30 years researchers of the Swiss Federal Institute for Environmental Science and Technology (EAWAG) in Dübendorf have been developing and applying trace analytical methods for the determination of individual organic contaminants in wastewaters and in the aquatic environment [1-6]. The overall goal of these studies is to provide measured environmental concentrations for environmental risk

${ }^{\star}$ Correspondence: Prof. W. Giger

Swiss Federal Institute for Environmental Science and Technology

EAWAG

Überlandstrasse 133

$\mathrm{CH}-8600$ Dübendorf

Tel.: + 4118235475

Fax: + 4118235311

E-Mail: giger@eawag.ch assessments of anthropogenic chemicals. In recent years the emphasis was on so-called emerging contaminants including pharmaceuticals such as antibiotics [7], endocrine disruptors (e.g. steroid hormones, nonylphenol, bisphenol A) and on various additives such as hardeners in foundry sands [8] or concrete admixtures [9], anticorrosives, and flame retardants. In all these studies the analytical methods were applied in elaborate field studies in wastewaters and natural waters. Major research objectives were to apply the results for input recognition and apportionment, to achieve mass balances and for process-oriented interpretations.

Human-use pharmaceuticals enter sewage effluents via urine and feces and by improper disposal. These pharmaceuticals are discharged from private households and from hospitals. In Switzerland and many developed countries sewage effluents mainly reach wastewater treatment plants (WWTPs) (Fig. 1). However, direct inputs into natural waters are also possible during rain events and this normally occurs in less industrialized countries. In wastewater treatment plants the antibiotics are only partially eliminated and residual amounts can reach ambient waters or groundwater. Most pharmaceuticals are found in natural waters in only very low concentrations. Despite this general finding, the question arises what risks these traces of pharmaceuticals pose for aquatic ecosystems. Antibiotics are of particular interest because we do not currently know whether their presence in natural waters contributes to the spread of antibiotic resistance of microorganisms.

Hirsch et al. [10] initially investigated the occurrence of several representatives from the main groups of antibiotics in wastewater treatment plant effluents and in river water. They described the analysis of various water samples for 18 antibiotic substances from the antibiotic classes of macrolides, sulfonamides, penicillins and tetracyclines. They observed the frequent occurrence of erythromycin- $\mathrm{H}_{2} \mathrm{O}$, roxithromycin and sulfamethoxazole with concentrations up to $6 \mu \mathrm{g} / \mathrm{l}$ in WWTP effluents. Neither tetracyclines nor penicillins could be detected at concentration levels above 50 and 20 ng/l, respectively. Penicillins are 
not very likely to occur in the aquatic environment due to the chemically unstable $\beta$ lactam ring, which is readily susceptible to hydrolytic cleavage. Sacher and coworkers [11] analyzed 105 groundwater wells in Baden-Wuerttemberg, Germany. Among 60 pharmaceuticals, they found erythromycin- $\mathrm{H}_{2} \mathrm{O}$ and sulfamethoxazole, which were the only antibiotics out of eight compounds detected in at least three groundwater samples. Recently, a study was published [12] which shows the occurrence of 95 organic wastewater contaminants including pharmaceuticals in 139 streams across the USA. Among 31 antibiotics from the groups of tetracyclines, macrolides, sulfonamides, and fluoroquinolones, erythromycin- $\mathrm{H}_{2} \mathrm{O}$ and sulfamethoxazole were found in concentrations of up to 1.7 and 1.9 $\mu \mathrm{g} / \mathrm{l}$, respectively.

We collected use figures for antibiotics in Switzerland in order to assess the potential inputs of these chemicals into wastewaters. In 1997, approximately $90 \mathrm{t}$ of antibiotics were used in Switzerland $-38 \%$ in human medicine and $62 \%$ in veterinary medicine. The amount of antibiotics applied annually for human medicinal purposes is around $34 \mathrm{t}$ and has remained fairly constant since 1992. $\beta$-Lactam antibiotics including penicillins and cephalosporins are the largest fraction of humanuse antibiotics, accounting for approximately 18 t. Following are sulfonamides (5.5 t), macrolides (4.3 t), and fluoroquinolones $(4.8 \mathrm{t})$. The major human-use fluoroquinolones (FQs) consumed in Switzerland are ciprofloxacin and norfloxacin. In Switzerland, private consumption of macrolides in the year 1999 amounted to $1.7 \mathrm{t}$ of clarithromycin, $0.32 \mathrm{t}$ of azithromycin, $0.26 \mathrm{t}$ of spiramycin, $0.17 \mathrm{t}$ of erythromycin and $0.15 \mathrm{t}$ of roxithromycin. Additionally, unknown amounts of $20-40 \%$ are employed in hospitals.

Here we present an overview report on the current state of our projects encompassing fluoroquinolone and macrolide antibiotics, which are applied in human medicine. The Table lists the antibiotics that were studied in municipal and hospital wastewaters, sewage sludges and rivers. One preliminary article [7] and five full reports on our investigations have already been published elsewhere [13-17]. In our early work we have dealt with human- and veterinary-use antibiotics and demonstrated different input pathways of the two types of antibiotics [7][18]. Currently, we are focusing on antibiotics that are applied for medicinal purposes in hospitals and by individual humans.

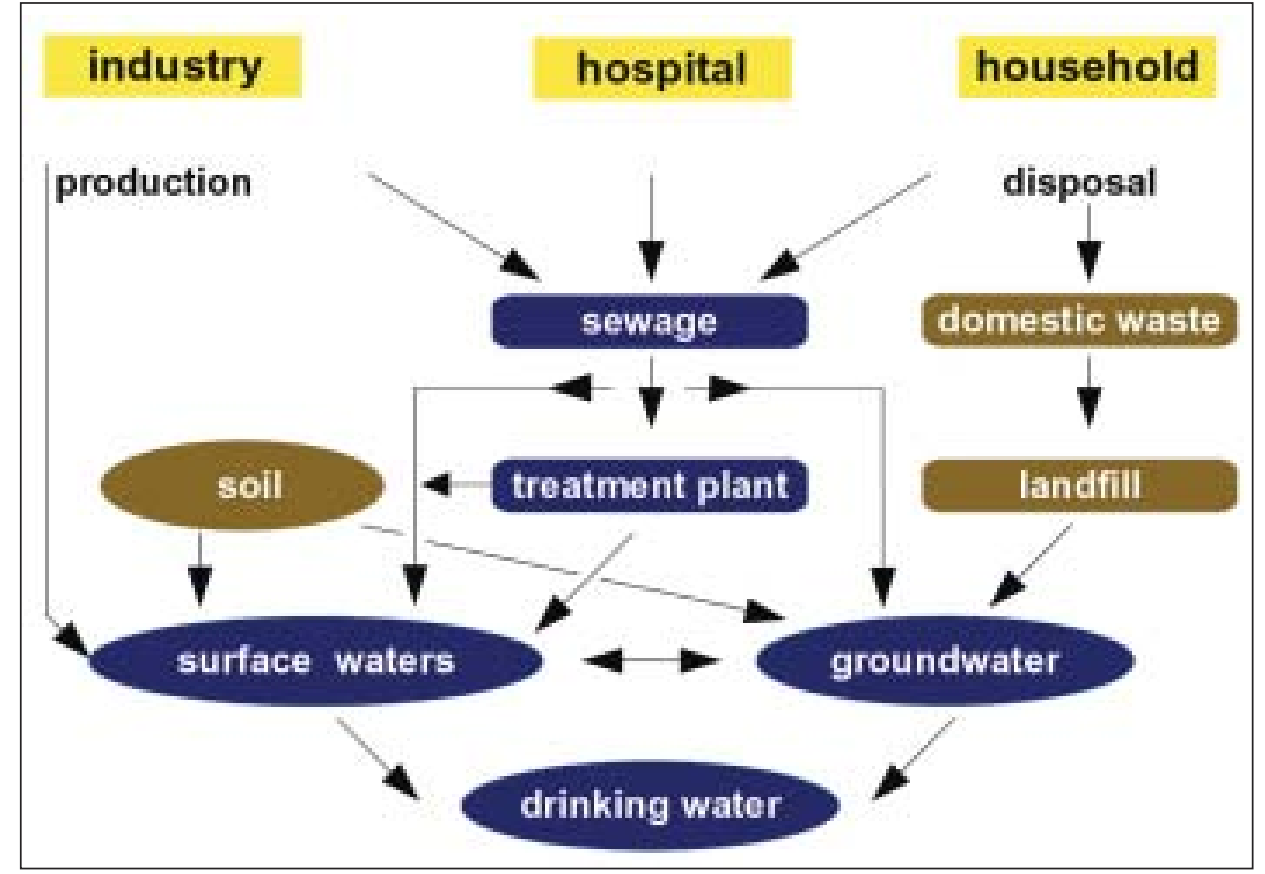

Fig. 1. Exposure routes of human-use antibiotics into wastewaters and the environment.

Table. Human-use antibiotics studied in wastewaters and in the aquatic environment

\begin{tabular}{|c|c|c|c|}
\hline Analytes & Samples & $\begin{array}{l}\text { Separation and detection techniques } \\
\text { Remarks }\end{array}$ & Ref. \\
\hline $\begin{array}{l}\text { Fluoroquinolones } \\
\text { Ciprofloxacin, norfloxacin }\end{array}$ & $\begin{array}{l}\text { HWW, MWW, } \\
\text { TWW, SS, S, } \\
\text { SW }\end{array}$ & LC/FLD, LC/MSMS & $\begin{array}{l}{[7][13-16]} \\
{[19-21]} \\
{[23]}\end{array}$ \\
\hline $\begin{array}{l}\text { Macrolides } \\
\text { Clarithromycin, } \\
\text { erythromycin- } \mathrm{H}_{2} \mathrm{O} \\
\text { roxithromycin }\end{array}$ & $\begin{array}{l}\text { HWW, TWW, } \\
\text { SW }\end{array}$ & LC/MS, LC/MSMS & {$[7][17]$} \\
\hline $\begin{array}{l}\text { Sulfonamides } \\
\text { sulfamethoxazole, } \\
\text { sulfamethazine }\end{array}$ & $\begin{array}{l}\text { TWW, } \\
\text { SW }\end{array}$ & $\begin{array}{l}\text { LC/MS } \\
\text { sulfamethazine from veterinarian use }\end{array}$ & [7] \\
\hline $\begin{array}{l}\beta \text {-Lactams } \\
\text { Penicillins, cephalosporins }\end{array}$ & HWW & $\begin{array}{l}\text { LC/MSMS } \\
\text { low stability and persistence }\end{array}$ & [22] \\
\hline \multicolumn{4}{|c|}{$\begin{array}{l}\text { HWW: hospital wastewater; MWW: municipal wastewater; TWW: treated municipal waste- } \\
\text { water; SS: sewage sludge; S: soil; SW: surface water (rivers, lakes) } \\
\text { LC/FLD: liquid chromatography/fluorescence detection, GC/MS: gas chromatography/mass } \\
\text { spectrometry, LC/MS: liquid chromatography/mass spectrometry; LC/MSMS: liquid chro- } \\
\text { matography/tandem mass spectrometry }\end{array}$} \\
\hline
\end{tabular}

\section{Fluoroquinolones}

An analytical method for the trace determination of fluoroquinolones (FQs) was developed based on reversed-phase liquid chromatography with fluorescence detection [13]. The simultaneous determination of nine FQs and the quinolone pipemidic acid in urban wastewater was accomplished. LC/FLD proved to be a specific, sensitive and quantitative method for the determination of trace amounts of a wide variety of FQs in wastewater effluents. En- richment using the mixed-phase cation-exchange disk cartridges was shown to be the most appropriate extraction procedure for FQs in wastewaters. The developed method was successfully applied to quantify FQs in effluents of urban wastewater treatment plants and in ambient waters [14].

Out of the ten investigated compounds, the FQs ciprofloxacin and norfloxacin could be determined quantitatively in urban wastewater treatment plant effluents. The identity of FQs in urban wastewater was confirmed by recording full fluorescence 
spectra and liquid chromatography directly coupled to tandem mass spectrometry. Both ciprofloxacin and norfloxacin are derived from human-use medication, contributing to around $90 \%$ of the FQs consumed in Switzerland. Not surprisingly, none of the investigated veterinarian-use FQs were detected in urban wastewater, because of the different entry route of veterinary drugs into the environment (i.e. via manure dispersion and animal excretion onto soils). Newly emerging FQs (e.g. gemifloxacin, moxifloxacin) can be integrated into the described method and quantified without the need for major changes. The presented FQ method is easily applicable, because sample enrichment is simple and fast, the separation is reliable, and the detection is highly sensitive.

Preceded by an efficient extraction procedure such as accelerated solvent extraction (ASE), the developed method could also serve to determine FQ contents in sewage sludges and in sludge-treated soils [15][20]. A $50 \mathrm{mM}$ aqueous phosphoric acid/ acetonitrile mixture $(1: 1)$ was found to be optimum in combination with an extraction temperature of $100{ }^{\circ} \mathrm{C}$ at $100 \mathrm{bar}$, during 60 and 90 min for sewage sludge and sludge-treated soil samples, respectively. A cleanup step using solid-phase extraction substantially improved the selectivity of the method. This method was successfully applied to untreated and anaerobically digested sewage sludges and sludge-treated soils. Ciprofloxacin and norfloxacin were found in sewage sludges from several wastewater treatment plants at concentrations ranging from 1.4 to $2.4 \mathrm{mg} / \mathrm{kg}$ of dry matter. Therefore, FQs may reach the terrestrial environment as indicated by the occurrence of FQs in topsoil samples from experimental fields, to which sewage sludge had been applied [16]. Fig. 2. shows the LC-FLD result for an extract of a topsoil sample (0-2.5 $\mathrm{cm})$ collected 21 months after sludge application from an experimental grassland plot.

The behavior of fluoroquinolone antibacterial agents during mechanical-biological wastewater treatment was studied by mass flow analysis [16][21]. Concentrations of FQs in filtered wastewater (raw sewage, primary, secondary, and tertiary effluents) and in suspended solids, sewage sludge (raw, excess, and anaerobically digested sludge), and sludge-treated soils were determined. Mass balance results are shown in Fig. 3. Wastewater treatment resulted in a reduction of the FQ mass flow of $88-92 \%$, mainly due to sorption on sewage sludge. No significant removal of FQs occurred under methanogenic conditions of the sludge digesters.

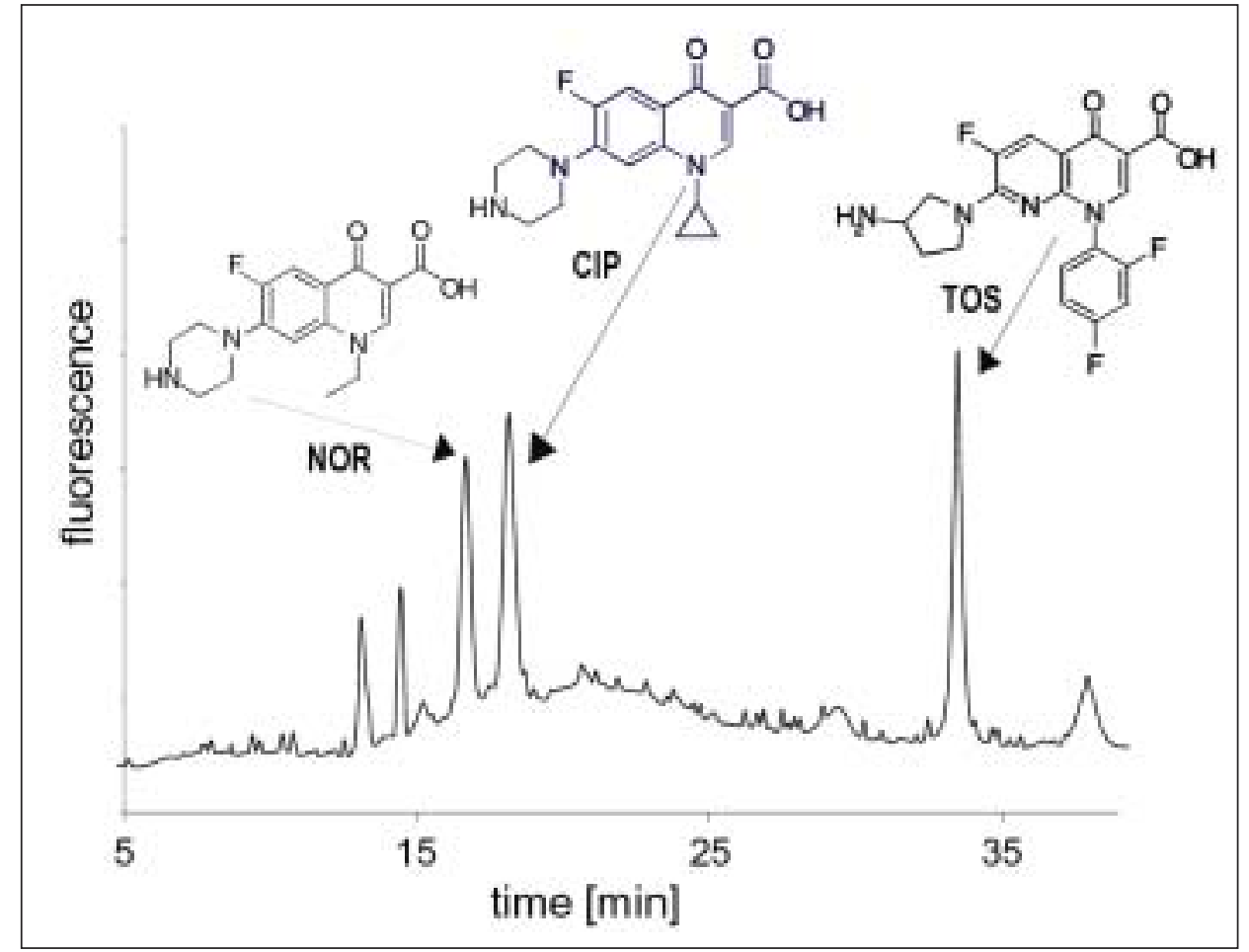

Fig. 2. LC-FLD chromatogram of a topsoil sample $(0-2.5 \mathrm{~cm})$ collected 21 months after sludge application from the experimental field at the Reckenholz area. Determined concentrations: $0.27 \mathrm{mg} / \mathrm{kg} \mathrm{d.m}$. ciprofloxacin and $0.30 \mathrm{mg} / \mathrm{kg} \mathrm{d.m.} \mathrm{norfloxacin} \mathrm{[15].} \mathrm{(Repro-}$ duced with permission from Anal. Chem. 2002, 74, 5455-5462 Copyright 2001 Am. Chem. Soc.)

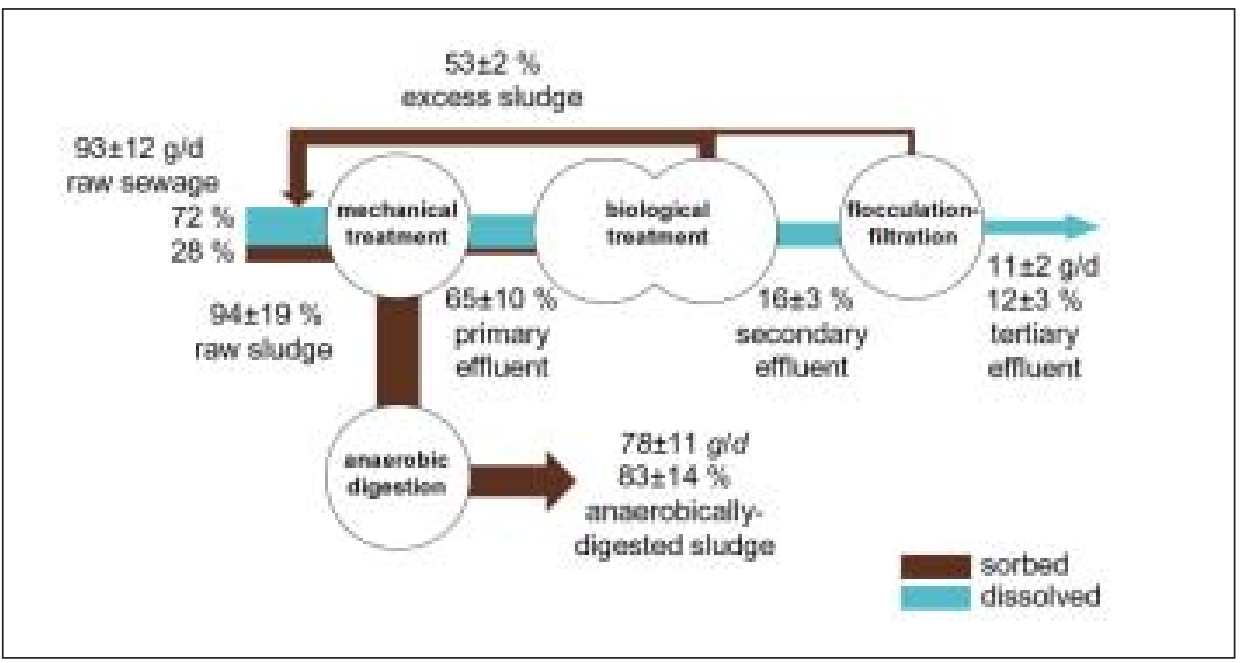

Fig. 3. Absolute loads in $\mathrm{kg} / \mathrm{d}$ and relative mass transfer of ciprofloxacin through mechanical treatment, biological treatment, flocculation-filtration, and anaerobic sludge digestion in Zürich-Werdhölzli WWTP (100\% equal to single ciprofloxacin-input mass flow entering the WWTP). For details see [16][21].

These results suggest sewage sludge as the main reservoir of FQ residues and indicate the importance of sludge management strategies to determine whether most of the human-excreted FQs enter the environment. Because of potential adverse effects of sewage sludge constituents a revision of the European Union Directive 86/278/EEC is planned to limit the amount of organic micropollutants released to the environ- ment by sewage sludge disposal. However, pharmaceuticals are not included in the directive. A more rigorous decision has been taken in Switzerland, where the disposal of sewage sludge into agricultural fields has been forbidden since January 2003. Nonetheless, as long as such a disposal practice occurs in many countries, a better knowledge on the fate and effects of chemicals in sludge-treated soils is needed. 
Mass flows of FQs were investigated in the aqueous compartments of the Glatt valley watershed, a densely populated region in Switzerland [14][19]. FQ concentrations and loads were determined in municipal wastewater effluents and in the receiving surface water, the Glatt river. Individual concentrations in raw sewage and in final wastewater effluents ranged from 255 to $568 \mathrm{ng} / \mathrm{l}$ and from 36 to $106 \mathrm{ng} / \mathrm{l}$, respectively. In the Glatt river, the FQs were present at concentrations below $19 \mathrm{ng} / \mathrm{l}$. The removal of FQs from the water stream during wastewater treatment was between 79 and $87 \%$. During the studied summer period, FQs in the dissolved fraction were significantly reduced downstream in the Glatt river (15-20 h residence time) (66\% for ciprofloxacin and $48 \%$ for norfloxacin) (see Fig. 4). Thus, after wastewater treatment, during the transport in rivers an additional decrease occurs of residual levels of FQs in the aquatic environment.

Fig. 5 shows the decrease of the measured concentrations along the exposure route from hospital wastewater to wastewater treatment and finally to river water. The concentrations of ciprofloxacin in grab samples of the hospital outflow were reduced up to two orders of magnitude by dilution before entering the WWTP. The WWTPs proved to be efficient removal barriers for the FQs before entering the Glatt. As mentioned above, the removal of FQs in the WWTPs is mainly due to sorption on sewage sludge.

The exposure data of ciprofloxacin for final effluents and river water were related to acute toxicity for aquatic organisms. Following the recommendations of the European guidelines and draft documents a predicted no effect concentration (PNEC) in surface waters of $3 \mu \mathrm{g} / 1$ using EC $_{50}$ (growth inhibition) data to the algae Selenastrum capricornutum was calculated. A PNEC in WWTPs of $8 \mu \mathrm{g} / \mathrm{l}$ using $\mathrm{EC}_{50}$ (growth inhibition) data to a relevant bacterial population of Pseudomonas putida was obtained. These values are comparable to the lowest found minimum inhibition concentration (MICs) for ciprofloxacin (MIC $\geq 10 \mu \mathrm{g} / \mathrm{l}$ ) without applying further safety factors or with a MIC of $1 \mu \mathrm{g} / \mathrm{l}$ when applying a safety factor of 10 which should account for uncertainties derived from intra-species variability. As shown in Fig. 5, only the concentrations in hospital wastewaters exceed the calculated PNEC range (risk quotient $\mathrm{MEC} / \mathrm{PNEC}>1$ )

However, such a risk characterization is limited to one compound. Since FQs are very much related - structurally as well as in their mode of action, the total FQ concentration should be considered in order to

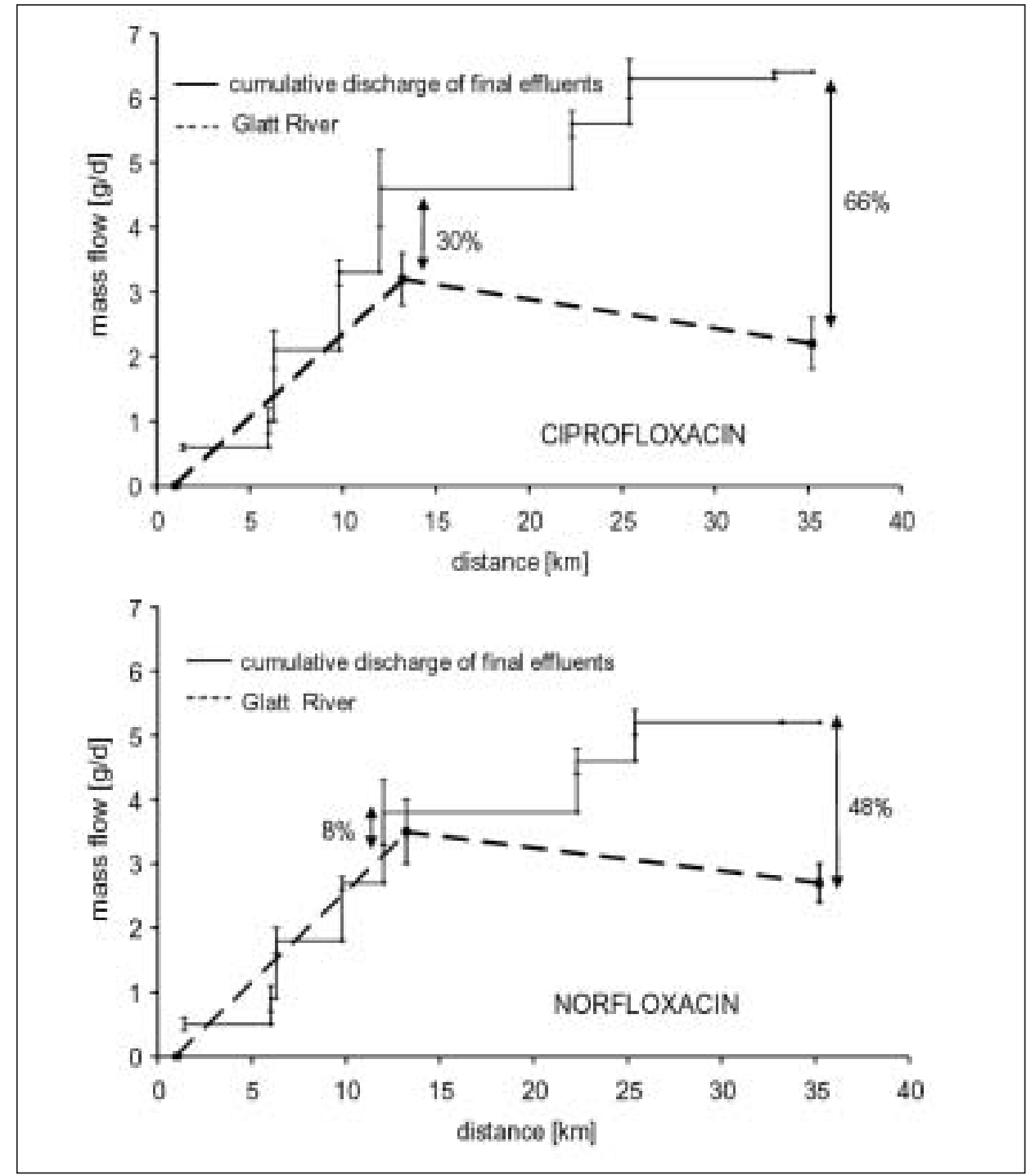

Fig. 4. Longitudinal (distance downstream from source) mass flow profiles of ciprofloxacin and norfloxacin in the Glatt valley watershed. Average values during a 4-day period (August 20-23, 2001) and respective standard deviations are plotted [14]. (Reproduced with permission from Env. Sci Technol. 2002, 5, 3645-3651. Copyright 2002 Am. Chem. Soc.)

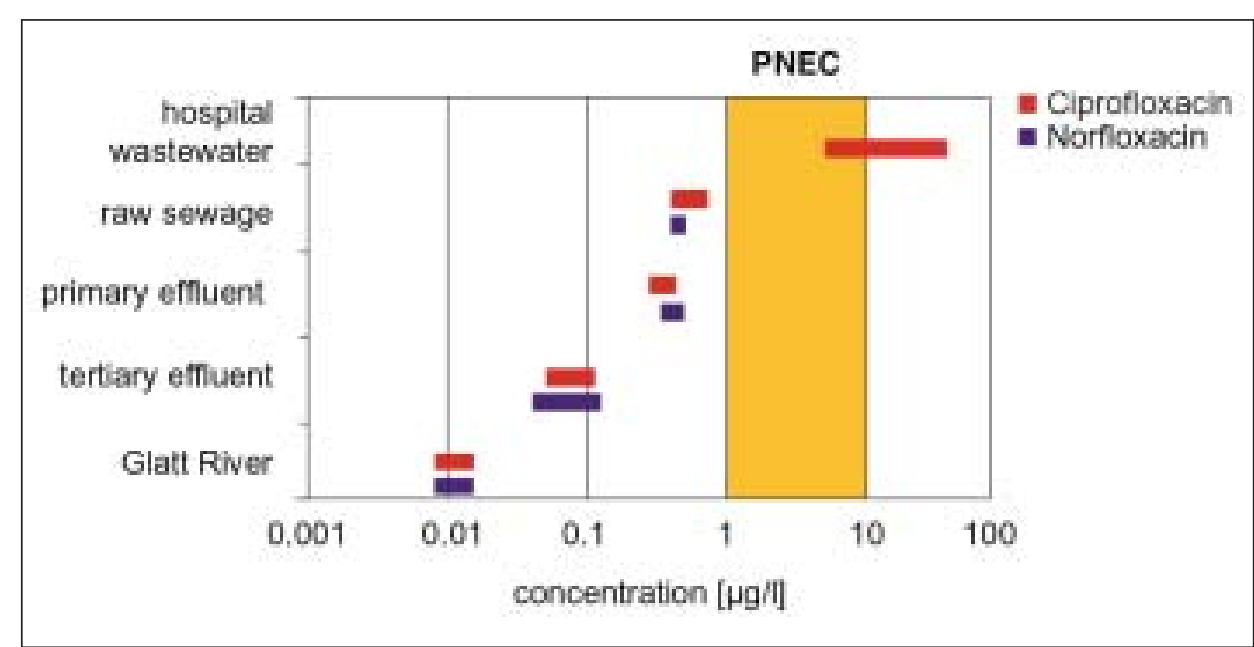

Fig. 5. Concentration ranges and predicted no effect concentrations (PNEC) of ciprofloxacin and norfloxacin in wastewater and in the aquatic environment. 
account for potential additive toxicity of FQs. For a more advanced and more sophisticated risk characterization, data on mixture toxicities as well on subinhibitory effects would be needed.

\section{Macrolides}

The analytical method for macrolide antibiotics developed by Hirsch et al. [10], which uses LC/MS/MS for analysis, was adapted for analyzing environmental samples by LC/MS [17]. Due to the fact that no tandem mass spectrometer was available in our institute when this project started, we had to restrict our investigations to biologically treated wastewater effluents. Interfering peaks in the chromatograms make it necessary to use an approach based on LC coupled to a tandem MS system for analyses of nontreated or only mechanically treated wastewater samples. We found the following macrolide concentrations in secondary WWTP effluents (i.e. mechanically and biologically treated wastewaters): 57 to $328 \mathrm{ng} / \mathrm{l}$ clarithromycin, nondetectable to $287 \mathrm{ng} / \mathrm{l}$ erythromycin- $\mathrm{H}_{2} \mathrm{O}$ and nondetectable to $72 \mathrm{ng} / \mathrm{l}$ roxithromycin (for details see [17]. As already had been observed by other authors [10], erythromycin was only present as the metabolite after water cleavage (erythromycin- $\mathrm{H}_{2} \mathrm{O}$ )
Fig. 6 shows the macrolide loads detected in three WWTPs in the Canton of Zürich. The plants Zürich-Werdhölzli and Dübendorf show macrolide distributions with clarithromycin being about ten times more abundant than erythromycin and roxithromycin. This pattern corresponds well with the use numbers for the individual macrolides in Switzerland. The annual average uses per person in Switzerland in 1999 were 246, 24, and $21 \mathrm{mg}$ for clarithromycin, erythromycin, and roxithromycin, respectively. However, these numbers are based only on private consumption and do not include use in hospitals.

Looking at daily loads (g/d in Fig. 6), one observes that in WWTP Zürich-Werdhölzli a much higher load of clarithromycin (almost $50 \mathrm{~g} / \mathrm{d}$ ) was found than in the other two other WWTP effluents ( 1.5 to $2.0 \mathrm{~g} / \mathrm{d}$ ). This difference is mainly caused by the larger size of the Zürich-Werdhölzli plant, which treats the bulk of the wastewaters of the city of Zürich. The calculation of relative loads (milligram per year and inhabitant in Fig. 6) yielded for Zürich-Werdhölzli a three times larger mass flows of 60 $\mathrm{mg} / \mathrm{y} \cdot \mathrm{inh}$ than for the other two plants (15-25 mg/y.inh). We infer that this difference is caused by the wastewater contributions both from the many people commuting to work in the city of Zürich (about 175 '000 people) and the twelve hospitals situated in Zürich including three of a relatively large size. No hospitals are situated at Dübendorf, Kloten or Opfikon and much fewer people commute to these towns.

The WWTP Kloten-Opfikon is a particular case, because it receives the wastewaters of the main international airport of Switzerland (Zürich Unique). This special wastewater source most probably has a significant impact on the occurrence of macrolides in the treated effluents. As shown in Fig. 6, the erythromycin- $\mathrm{H}_{2} \mathrm{O}$ load surpasses the corresponding values for clarithromycin. This finding could be rationalized by input estimates based on information concerning the passengers' nationalities of origin, on the destination of the flights arriving at and departing from Zürich Unique and on the macrolide uses in the respective countries.

The results of two sampling campaigns at the WWTP Kloten-Opfikon showed that during the winter season two times higher loads of macrolide antibiotics were observed than in summer [17]. This difference can best be explained by the seasonal variation of the use figures of these pharmaceuticals, as documented by the monthly sales data showing that macrolides are sold in two times higher amounts in January/February than in summer. This seasonal effect arises because the macrolide antibiotics are mainly used to cure infections of the respi-

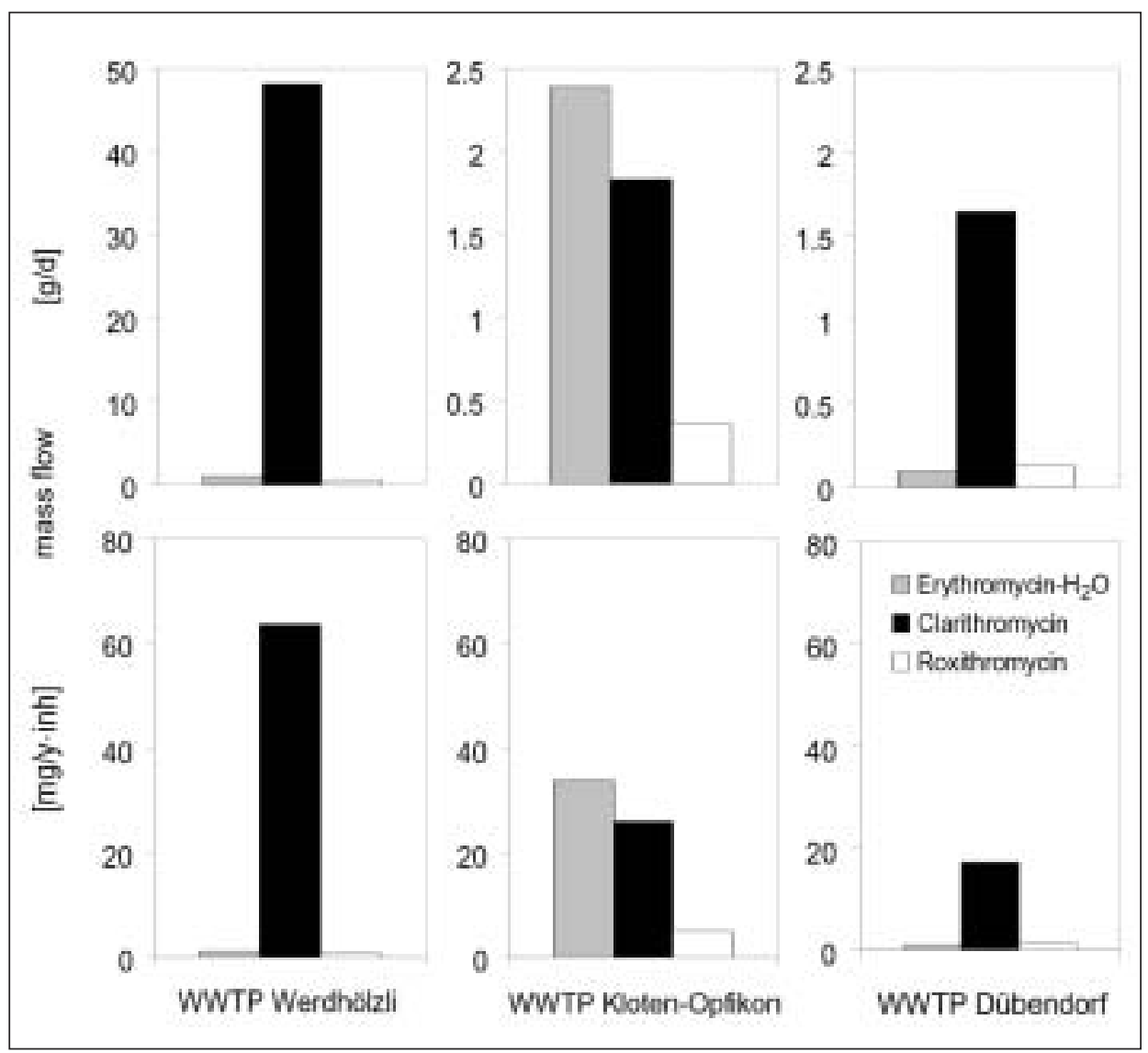

Fig. 6. Loads of macrolides in three mechanically and biologically treated effluents of WWTPs: Zürich-Werdhölzli, Kloten-Opfikon, and Dübendorf. Units are grams per day and $\mathrm{mg}$ per year and inhabitant living in the catchment area. For detailed information see McArdell et al. [17]. 
ratory tract. Based on the detected seasonal and regional differences of the macrolide wastewater loads and eventual varying concentrations in ambient waters, we postulate that such variations must be considered for environmental exposure assessments.

Analyses of water samples from the Glatt river contained clarithromycin concentrations from 7 to $75 \mathrm{ng} / \mathrm{l}$. Using flow rate data of the Glatt river, we could calculate clarithromycin loads along a river stretch of $12 \mathrm{~km}$ starting at the Greifensee outlet. The clarithromycin loads increased from 7.8 to $25.6 \mathrm{~g} / \mathrm{d}$. The inputs of all WWTPs between these two sampling points were measured yielding a total additional load of $23.9 \mathrm{~g} / \mathrm{d}$. The derived removal of $20 \%$ is not considered statistically significant because of the uncertainties involved with the chemical determination of trace contaminants and with measuring river flow rates. No clarithromycin elimination was observed in the lower part of the river. These results contrast with the corresponding measurements of the fluoroquinolone antibiotics ciprofloxacin and norfloxacin in the same watershed [14]. Significantly lower concentrations and loads of ciprofloxacin and norfloxacin (max. $10 \mathrm{~g} /$ day in winter) and substantial eliminations were observed in the Glatt river.

In 2001, WWTP Zürich-Glatt was closed down, and the wastewater was diverted from the Glatt to the WWTP Werdhölzli with the Limmat river as receiving water. As a consequence, the input of treated wastewater into the Glatt river was drastically reduced, since WWTP Zürich-Glatt contributed with $40 \%$ to the total amount of treated wastewater discharged to the river. To follow the reduced input of wastewater into the Glatt river due to the closure of the WWTP, samples were taken for the determination of macrolide antibiotics in the
Glatt river at three sampling locations before and after the diversion. The results (Fig. 7) indicate that after the diversion a clear reduction of the clarithromycin loads could be observed. At the sampling station in Oberglatt, which is located below the effluent of WWTP Zürich-Glatt, the average load of clarithromycin was reduced by 13.9 $\mathrm{g} / \mathrm{d}(54 \%)$ between winter 2001 and winter 2002. At the sampling station in Rheinsfelden a reduced load of $16.7 \mathrm{~g} / \mathrm{d}(47 \%)$ was measured. These lower clarithromycin loads are a consequence of the reduction of discharge of wastewater into the Glatt river caused by the closure of the WWTP ZürichGlatt.

We can infer from our results that macrolide antibiotics are not fully eliminated in WWTPs and that therefore residual amounts occur in the receiving surface waters, in which macrolide antibiotics are not substantially removed. Therefore the goal of decreasing the levels of antibiotics in ambient waters can only be achieved by reducing inputs from WWTPs. One possibility to achieve this would be a special treatment of hospital wastewaters.

\section{On-going and Future Research}

Ongoing studies aim at enlarging our knowledge on the elimination processes of antibiotics during wastewater treatment including sorption onto sewage sludge and biotransformation. An analytical method based on LC/MSMS is being developed for determining both sulfonamides and macrolides in nontreated and treated wastewaters. One study focuses on the behavior of antibiotics in a WWTP, in which conventional activated sludge treatment followed by a sand filter is operated in parallel to a pilot-scale membrane bioreactor. In a similar way a fixed bed plant (biofilter) is being investigated. These activities are performed in cooperation with the EU-project POSEIDON (Assessment of Technologies for the Removal of Pharmaceuticals and Personal Care Products in Sewage and Drinking Water Facilities to Improve the Indirect Potable Water Reuse, www.euposeidon.com)

The $\beta$-lactams are highly important based on the available use data, but have not yet been found in wastewater effluents and in the aquatic environment. Short halflives in aqueous matrices caused by fast chemical and microbial degradation, such as hydrolysis of the $\beta$-lactam ring, is probably the main reason. A lack of appropriate and sensitive analytical methods may be another reason. A method was developed for the analysis of $\beta$-lactams in hospital wastewaters and needs to be further validated. First results show the occurrence of some $\beta$-lactams in hospital wastewaters at concentrations of up to $30 \mu \mathrm{g} / 1$ [22]. Hospital wastewaters will be analyzed in order to follow the dynamic occurrence and fate of the persistent fluoroquinolones together with the relatively labile $\beta$-lactams. For that purpose, the analytical methods will be merged into one procedure. Major metabolites of sulfonamides and $\beta$-lactams will also be studied in wastewaters and in degradation experiments in the laboratory.

Preliminary studies in cooperation with the Cantonal Institute of Microbiology in Bellinzona yielded results regarding the correlation of antibiotic concentrations and the occurrence of antibiotic resistance in hospital wastewaters [23] [24]. It will be an important objective to address questions regarding the effects of environmental antibiotic concentrations in an interdisciplinary approach. There will also be efforts to evaluate potential risks associated with the combined occurrence of several antibiotics at subinhibitory concentrations. These

Fig. 7. Clarithromycin loads at three sampling stations in the Glatt river before (winter 2001), and after full closure (winter 2002) of WWTP Zürich-Glatt. 
studies are part of the National Research Program on 'Antibiotic Resistance' (http://www.snf.ch/NFP/NFP49/Home_d. html).

\section{Acknowledgments}

The financial support of Bayer AG (Germany) is gratefully acknowledged. We thank Abbott GmbH (Wiesbaden, Germany) for supplying clarithromycin. Partial funding for the macrolide and $\beta$-lactam studies came from the Swiss National Science Foundation through its National Research Program 'Antibiotic Resistance' (NRP 49, project on 'Occurrence of Human-Use Antibiotics and Antibiotic Resistance in the Aquatic Environment, HUMABRA'). We appreciate very much the good collaboration with the operators of the wastewater treatment plants.

Received: August 19, 2003
[18] M.Y. Haller, S.R. Müller, C.S. McArdell, A.C. Alder, M.J.-F. Suter, J. Chromatogr. A 2002, 952, 11.

[19] E.M. Golet, Ph. D. Thesis, ETH Zürich No. 14690, 2002.

[20] A. Strehler, Diploma Thesis, ETH Zürich, 2001.

[21] I. Xifra, Diploma Thesis, University Girona, Spain, 2000.

[22] H. Kuch, A.C. Alder, C.S. McArdell, H.-P E. Kohler, W. Giger, 2003, unpublished results, EAWAG.

[23] N.A. Pham Thi, Master Thesis, Ecole Polytechnique Fédérale de Lausanne, 2003.

[24] R. Peduzzi, A. Demarta, V. Gaia, A.R. Corvaglia, "Role of Residual Antibiotics in Aquatic Environments on Selection and Diffusion of Bacterial Resistance,' project RASDI of NRP 49.

[1] W. Giger, M. Reinhard, C. Schaffner, W. Stumm, Environ. Sci. Technol. 1974, 8, 454.

[2] W. Giger, E. Molnar-Kubica, Bull. Environ. Contam. Toxicol. 1978, 19, 475.

[3] K. Grob, K.G.Grob, Jr., J. Chromatogr. A 1975, 106, 299

[4] W. Giger, Chimia 1997, 51, 729

[5] M.J.-F. Suter, A.C. Alder, M. Berg, C.S. McArdell, S. Riediker, W. Giger, Chimia 1997, 51, 871.

[6] A.C. Alder, H. Siegrist, K. Fent, T. Egli, E. Molnar, T. Poiger, C. Schaffner, W. Giger, Chimia 1997, 51, 922

[7] A.C. Alder, C.S. McArdell, E.M. Golet, S Ibric, E. Molnar, N.S. Nipales, W. Giger, in 'Pharmaceuticals and Personal Care Products in the Environment: Scientific and Regulatory Issues', Eds. C.G. Daughton, T. Jones-Lepp, Symposium Series 791, Am. Chem. Soc., Washington D.C., USA, 2001.

[8] S. Riediker, M.J.-F. Suter, W. Giger, Wat. Res. 2000, 34, 2069.

[9] S. Ruckstuhl, M.J.-F. Suter, H.-P.E. Kohler, W. Giger, Environ. Sci. Technol. 2002, 36, 3284

[10] R. Hirsch, T. Ternes, K. Haberer, K.-L. Kratz, Sci. Total Environ. 1999, 225, 109.

[11] F. Sacher, F.T. Lange, H.-J. Brauch, I. Blankenhorn, J. Chromatogr. A 2001, 938 199.

[12] D.W. Kolpin, E.T. Furlong, M.T. Meyer E.M. Thurman, S.D. Zaugg, L.B. Barber, H.T. Buxton, Environ. Sci. Technol. 2002, 36, 1202.

[13] E.M. Golet, A.C. Alder, A. Hartmann, T.A Ternes, W. Giger, Anal. Chem. 2001, 73 , 3632.

[14] E.M. Golet, I. Xifra, H. Siegrist, A.C Alder, W. Giger, Environ. Sci. Technol. 2002, 36, 3645 .

[15] E.M. Golet, A. Strehler, A.C. Alder, W. Giger, Anal. Chem. 2002, 74, 5455.

[16] E.M. Golet, A.C. Alder, W. Giger, Environ. Sci. Technol. 2003, 37, 3243.

[17] C.S. McArdell, E. Molnar, M.J.-F. Suter, W. Giger, Environ. Sci. Technol. 2003, 37, in press. 